\title{
A Conceptual Approach to Eliminate Bypass Release of Fission Products by In-Containment Relief Valve under SGTR Accident
}

\author{
Taeseok Kim (i), ${ }^{1}$ Wonjun Choi ${ }^{(D)},{ }^{1}$ Joongoo Jeon $\left(\mathbb{D},{ }^{1}\right.$ Nam Kyung Kim $(\mathbb{D}){ }^{1}$ \\ Hoichul Jung, ${ }^{1}$ and Sung Joong Kim $\mathbb{D D}^{1,2}$ \\ ${ }^{1}$ Department of Nuclear Engineering, Hanyang University, Seoul 04763, Republic of Korea \\ ${ }^{2}$ Institute of Nano Science and Technology, Hanyang University, Seoul 04763, Republic of Korea \\ Correspondence should be addressed to Sung Joong Kim; sungjkim@hanyang.ac.kr
}

Received 22 March 2018; Accepted 18 July 2018; Published 6 August 2018

Academic Editor: Seong Wan Hong

Copyright (C) 2018 Taeseok Kim et al. This is an open access article distributed under the Creative Commons Attribution License, which permits unrestricted use, distribution, and reproduction in any medium, provided the original work is properly cited.

During a hypothesized severe accident, a containment building is designed to act as a final barrier to prevent release of fission products to the environment in nuclear power plants. However, in a bypass scenario of steam generator tube rupture (SGTR), radioactive nuclides can be released to environment even if the containment is not ruptured. Thus, thorough mitigation strategies are needed to prevent such unfiltered release of the radioactive nuclides during SGTR accidents. To mitigate the consequence of the SGTR accident, this study was conducted to devise a conceptual approach of installing In-Containment Relief Valve (ICRV) from steam generator (SG) to the free space in the containment building and it was simulated by MELCOR code for numerical analysis. Simulation results show that the radioactive nuclides were not released to the environment in the ICRV case. However, the containment pressure increased more than the base case, which is a disadvantage of the ICRV. To minimize the negative effects of the ICRV, the ICRV linked to Reactor Drain Tank (RDT) and cavity flooding was performed. Because the overpressurization of containment is due to heat of ex-vessel corium, only cavity flooding was effective for depressurization. The conceptual design of the ICRV is effective in mitigating the SGTR accident.

\section{Introduction}

Prevention or mitigation of fission product release is very important to guarantee ultimate safety of nuclear power plants (NPPs). Faithful to the Defence-in-Depth philosophy, a containment building is designed and constructed as the last barrier to prevent the fission product release under severe accident (SA) scenarios [1]. Many researchers have studied hazardous factor such as direct containment heating [2], steam explosion [3], hydrogen combustion [4], and overpressure [5]. These studies enhance reliability of the containment building.

However, in a hypothesized scenario of containment bypass, even if the containment building is not ruptured, fission products can be released to the environment. Representative bypass accidents are interfacing system loss of coolant accident (ISLOCA) and steam generator tube rupture (SGTR). ISLOCA is containment bypass accident where a pipeline connected to the reactor coolant system (RCS) is broken outside of the containment [6]. SGTR accident can release fission products to environment without containment rupture because pressure boundary of the primary system is not retained due to SGTR [7]. Due to characteristics of containment bypass accidents, some sensitivity studies of bypass were conducted $[8,9]$.

The SGTR accident, especially, can be induced by the other SAs. Station blackout (SBO) accident such as the one that occurred in Fukushima can induce SGTR with failure of turbine-driven auxiliary feed water (TDAFW) [10]. During an extreme situation of SBO transient, steam generator (SG) U-tube integrity could be threatened by thermally or pressure-induced creep rupture [11]. The SGTR accident induced by $\mathrm{SBO}$ releases more fission products to environment because many safety features such as auxiliary feed water (AFW) are inoperable. Therefore, to fortify the safety of the NPP during the SGTR accident, a more creative mitigation strategy needs to be devised. 


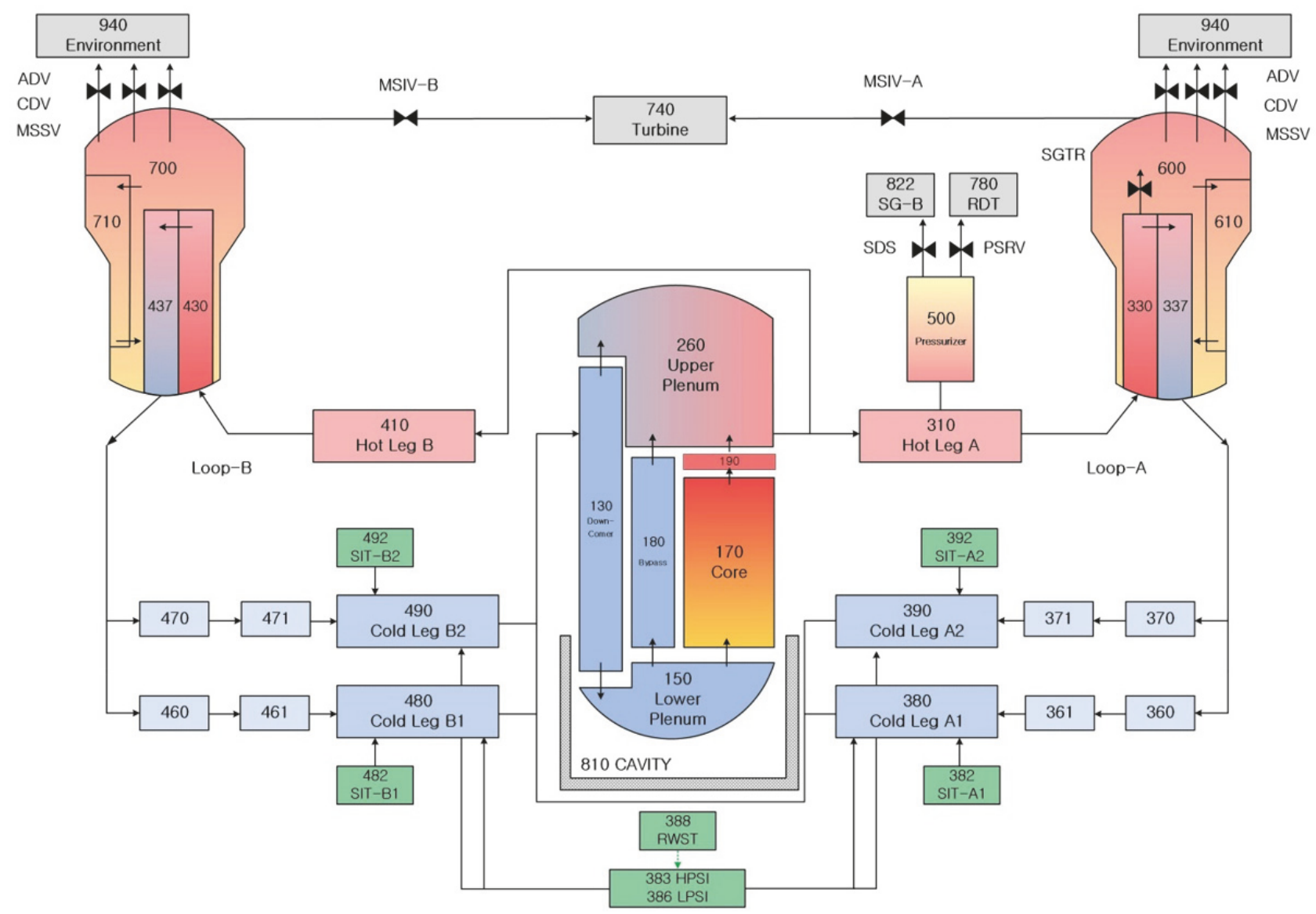

FIGURE 1: MELCOR nodalization of OPR1000.

In this study, a conceptual approach was taken to mitigate the consequence of SGTR accident by generating incontainment relief valve (ICRV). The ICRV is additional paths from SG to in-containment free space such as upper dome and reactor drain tank (RDT) for venting steam of the secondary system. To investigate its effectiveness in Optimized Power Reactor 1000 MWe (OPR1000) consisting of a major fleet of Korean operating NPPs, numerical simulation was conducted using MELCOR code.

\section{Numerical Methodologies}

2.1. MELCOR Code. MELCOR code is a SA analysis code developed for light water reactors (LWRs). Since 1982, Sandia National Laboratories have been developed for use in plant risk assessment and source term analysis for US Nuclear Regulatory Commission [12]. MELCOR can simulate various SA phenomena such as thermal-hydraulic response of the primary RCS, core uncovering, fuel heat-up, cladding oxidation, heat-up of the reactor pressure vessel (RPV) lower head by the molten core, lower plenum penetration, hydrogen production, and fission product release. Because of this usefulness in analyzing SA, MELCOR is usually used for uncertainty analysis and sensitivity studies [13]. In addition, many countries have used MELCOR for the regulation of
LWR [14]. Particularly, the Korean regulatory body has utilized MELCOR for monitoring and judgement of SAs $[15,16]$. Thus, in this study, MELCOR version 2.1 was used to investigate effectiveness and adverse effects of the ICRV.

2.2. MELCOR Input Model of OPR1000. The Korean pressurized water reactor (PWR) OPR1000 as a reference plant was modelled in MELCOR. OPR1000 nodalization consists of two loops of nuclear steam supply system and containment. Figure 1 shows a schematic nodalization of OPR1000 for the MELCOR simulation. The input model includes a core (control volume (CV) 170), a downcomer (CV 130), a lower plenum (CV 150), an upper plenum (CV 260), two hot legs (CV 310 and 410), four cold legs (CV 380, 390, 480, and 490 ), and a pressurizer (CV 500). Two SGs are composed of a primary side inlet (CV 330 and 430), outlet (CV 337 and 437), and secondary sides (CV 600, 700, 610, and 710). Safety features consist of four safety injection tanks (SITs; CV 382, 392, 482, and 492), high-pressure safety injection (HPSI; CV 383), and low-pressure safety injection (LPSI; CV 386) connected refuelling water tank (RWT; CV 388). In addition, AFW, the safety depressurization system (SDS), containment spray, the passive autocatalytic recombiner (PAR), pressurizer safety relief valve (PSRV), main steam safety valve (MSSV), and atmospheric dump valve (ADV) were also modelled 


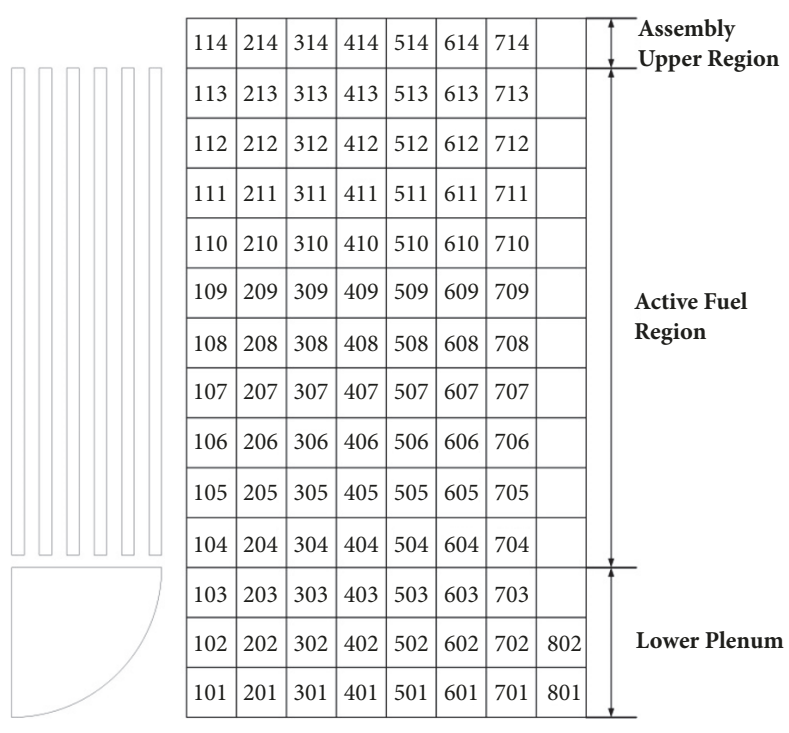

FIGURE 2: MELCOR nodalization for core.

to enable depressurization of the primary and secondary systems. MSSVs are operated above 8.6 MPa of SG pressure.

The core nodalization for MELCOR calculation included 7 radial rings and 14 axial levels (Figure 2). The lower plenum (CV 150) extended from the first to the third axial level, the core region (CV 170) extended from the fourth to thirteenth axial levels, and the fourteenth axial level of the core cell represented the upper region of the fuel assembly, from which the core exit temperature (CET) information was extracted. The lower plenum allows seven penetrations and hemispheric lower head type is optioned.

The nodalization of containment was based on the compartment configuration of the MAAP-CONTAIN analysis [4]. Figure 3 shows the nodalization of containment. It was also based on the layout of the containment building in the Final Safety Analysis Report (FSAR) for Shin Kori NPP Units 1 and 2 [17]. The 20 CVs were constructed according to the axial height and function of each compartment. The total volume of the $20 \mathrm{CVs}$ modelled was $77,420.92 \mathrm{~m}^{3}$, which is approximately the same as the containment volume specified in the FSAR.

2.3. Description of the SGTR Accident. The SGTR scenario was selected as the main accident scenario due to the bypassed release of radionuclides to the environment unlike other accident scenarios such as small break loss of coolant accident (SBLOCA), SBO, and total loss of feed water (TLOFW) [7]. To investigate effectiveness of a new mitigation strategy creating an ICRV, very conservative conditions with the SGTR scenario were applied in this simulation. First, the accident started with a complete break of one U-tube in SG, with flow area of $4.49 \times 10^{-4} \mathrm{~m}^{2}$. Second, the active safety systems such as HPSI, LPSI, and SDS were assumed to fail. Finally, AFW was assumed unavailable in the secondary system. Henceforth, only the passive safety features such as PSRV, MSSV, and SITs were assumed available in the

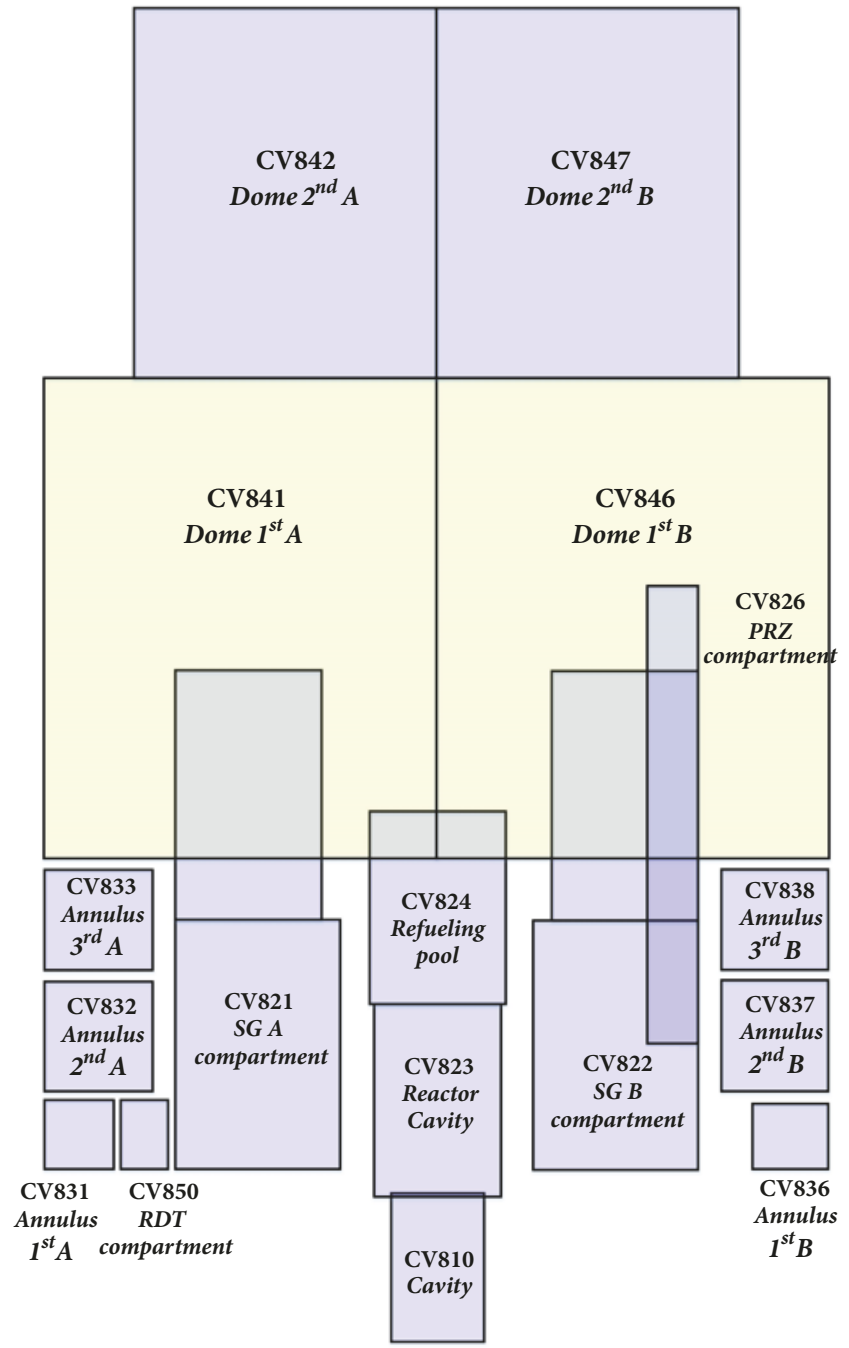

FIGURE 3: MELCOR nodalization for the OPR1000 containment.

simulation. Between a SG tube (CV330) and SG (CV600), a flow path was modelled to simulate the SGTR accident. Figure 4 shows the description of the steam generator tube rupture modelling.

2.4. Description of In-Containment Relief Valve (ICRV). To prevent release of the radioactive nuclides through MSSV, an ICRV was modelled in this study. The ICRV is connected between SG and in-containment space such as upper dome and RDT. If a case includes no ICRV (base case), the radionuclides contained in steam can be released to the environment directly via the MSSV. However, cases bearing the ICRV (ICRV case) do not allow release of radionuclide to the environment without containment rupture. This study was conducted with two types of the ICRV cases and a base case as shown in Figure 5. The base case includes MSSV to prevent overpressurization of the secondary system. The MSSV is connected between SG and the environment (Figure 5(a)). On the other hand, the ICRV cases model the ICRV instead of MSSV. One ICRV case has ICRV connected to upper dome in the containment (CNMT). The other case that has the 


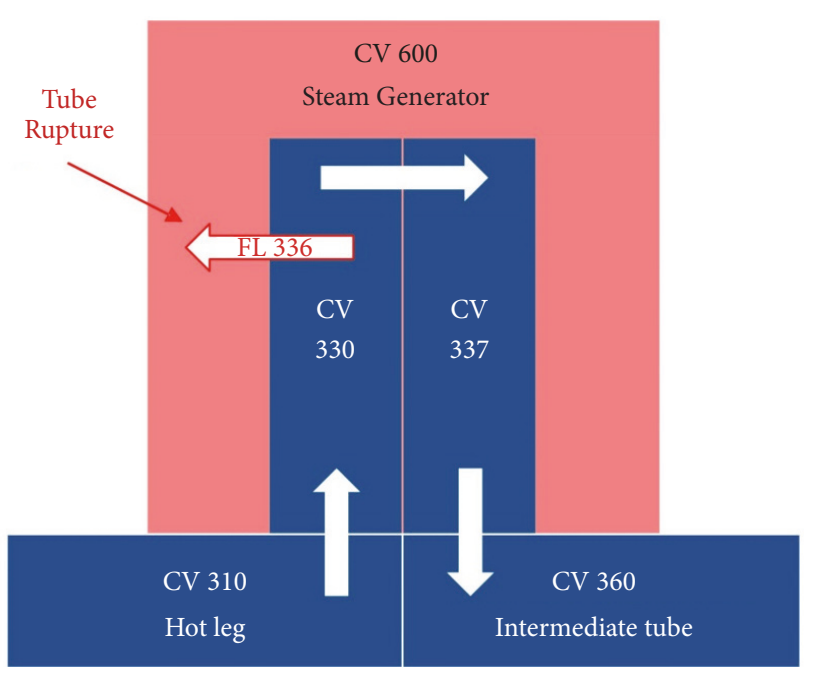

Figure 4: A schematic of the steam generator tube rupture in MELCOR input model.

TABLE 1: Comparison of major parameters between FSAR values and MELCOR calculation.

\begin{tabular}{lccc}
\hline Parameter & FSAR [17] & MELCOR & Error $(\%)$ \\
\hline Core thermal power $(\mathrm{MWt})$ & 2815 & 2815 & 0.00 \\
RCS pressure $(\mathrm{MPa})$ & 15.5 & 15.5 & 0.00 \\
Core inlet temperature $(\mathrm{K})$ & 569 & 573 & 0.70 \\
Core outlet temperature $(\mathrm{K})$ & 600 & 603 & 0.50 \\
Primary flow rate $(\mathrm{kg} / \mathrm{s})$ & 15,306 & 15,546 & 1.33 \\
Secondary side pressure $(\mathrm{MPa})$ & 7.37 & 7.37 & 0.00 \\
Steam flow rate per SG $(\mathrm{kg} / \mathrm{s})$ & 800 & 809 & 1.13 \\
\hline
\end{tabular}

valve is connected to RDT for heat removal of the steam using the RDT water. The condensation effect was especially investigated in the ICRV-RDT case because relatively small volume of the RDT may not accommodate the substantial amount of steam release from the SG if effective condensation of the steam does not occur. The path parameters such as flow area, length, and open pressure were determined based on the specifications of the MSSV.

\section{Results and Discussion}

3.1. Steady-State Calculation. Using the current MELCOR simulation, a steady-state calculation was performed to verify the suitability of the MELCOR nodalization of OPR 1000 . Steady-state operating conditions of OPR1000 from the MELCOR calculation were compared with corresponding values specified by the FSAR [17] and were summarized in Table 1. It was confirmed that the MELCOR results are in good agreement with the nominal FSAR values. Thus, the input model used in this study confirmed the suitability of current MELCOR nodalization of OPR1000 during the severe accident.

3.2. Base Case Simulation. The base case of SGTR scenario was simulated using MELCOR 2.1. Table 2 shows the accident sequences in base case. When the accident started, the

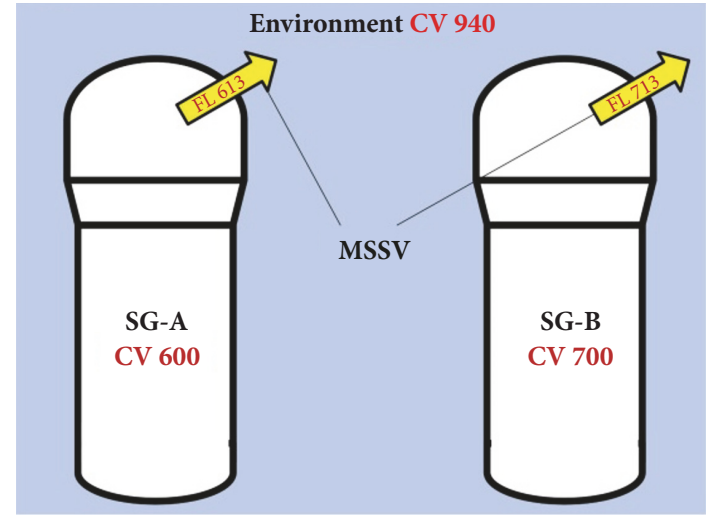

(a)

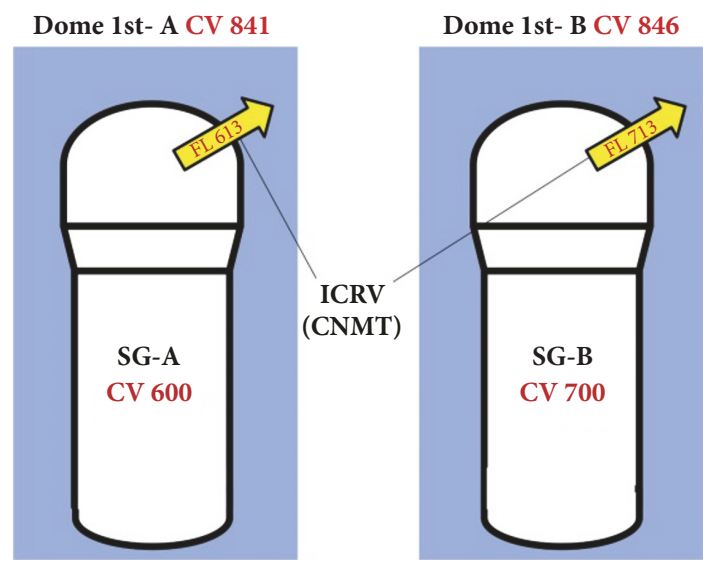

(b)

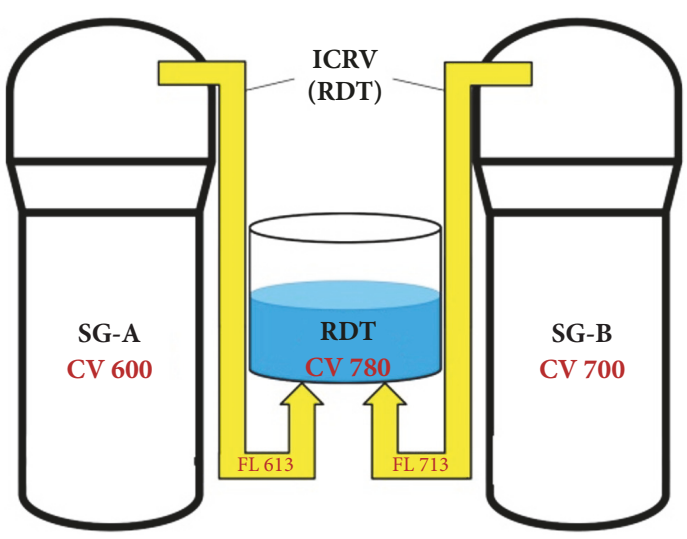

(c)

FIgURE 5: Schematic of simulation cases: (a) base case, (b) ICRVCNMT case, and (c) ICRV-RDT case.

primary coolant was transported to the secondary system. It increased the secondary pressure and decreased the RCS pressure. Then, a reactor trip occurred with MFW trip and MSIV closure. In this scenario, the AFW was assumed unavailable in the secondary system. Thus, a large amount of the steam was released into the environment through the MSSV. The RCP was stopped by cavitation after the reactor trip. The core was uncovered and heated because of loss of the coolant through the MSSV. As the primary 
TABLE 2: Accident sequences in the base case.

\begin{tabular}{lc}
\hline Accident sequence & SGTR base (s) \\
\hline Accident start & 0 \\
MFW trip & $2,654(0.74 \mathrm{~h})$ \\
Reactor trip & $2,654(0.74 \mathrm{~h})$ \\
MSSV open & $2,654(0.74 \mathrm{~h})$ \\
RCP trip & $2,672(0.74 \mathrm{~h})$ \\
Oxidation start & $12,437(3.45 \mathrm{~h})$ \\
Gap release & $12,644(3.51 \mathrm{~h})$ \\
Cladding melting & $13,872(3.85 \mathrm{~h})$ \\
Melt relocation & $14,328(3.98 \mathrm{~h})$ \\
RPV failure & $21,406(5.94 \mathrm{~h})$ \\
\hline
\end{tabular}

water was depleted and the core water temperature increased, zircaloy in the fuel cladding was highly oxidized by the high temperature steam. During this oxidation process, substantial amount of oxidation heat was generated, which accelerated the core damage. Subsequently, the fuels were subjected to extremely high temperature condition and the reactor core started to melt down and relocate to the lower plenum of the RPV. Finally, RPV failure was predicted by the thermal attack of molten corium in the penetration location.

Figure 6 shows the primary and secondary system pressure. In the early state of the accident, RCS pressure decreased by coolant release through the tube rupture. Without safety injection, coolability of the core was not maintained. Thus, the core temperature increased and the RCS pressure increased despite tube rupture. The coolant was released continuously to the environment through the MSSV and the system pressure decreased with time. After RPV failure, the system pressure rapidly decreased by ejection of the corium and the coolant. The secondary side pressure reached $8.6 \mathrm{MPa}$, which is the MSSV open pressure. The valve was kept open until RPV failure and secondary pressure rapidly decreased only in broken SG. In the broken SG side, the coolant was released to the outside of the RCS through the tube rupture. Thus, the pressure quickly decreased at the time of RPV failure. However, no mass transfer occurs in the intact SG side and thus the pressure was maintained although the RPV failed.

The tendency of the accident progress in terms of the water level of the SGs and reactor core is shown in Figure 7. Following the SGTR event, the primary system water crossed over the secondary system and thereby the primary system water level decreased. Before the reactor trip, the water level of the broken SG was not decreased because the MFW was not tripped and the MSIV was not closed. However, the water level of the broken and intact SGs rapidly decreased after the MFW trip and corresponding MSSV open. When the water level of the broken SG was reached to the SGTR set point, the residual water in the U-tube and that in hot- and cold-leg were evaporated together. Therefore, a very gradual decrease in water level was observed in the broken SGs between 2.5 to 6 hrs before RPV failure. Although the duration of the gradual decrease in water level is different, a similar tendency was reported in Wang et al.s study, which performed the SGTR

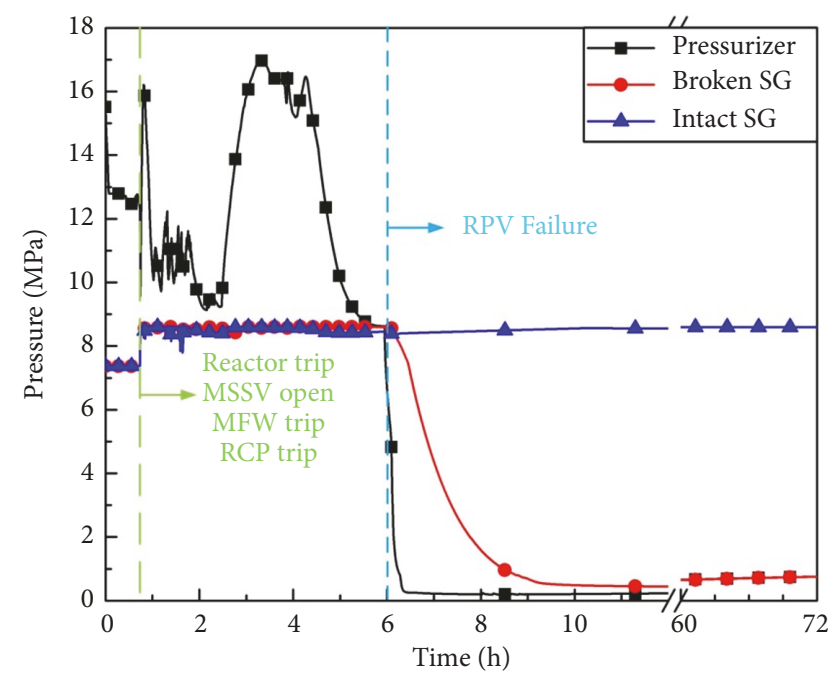

FIgURE 6: Pressure of the RCS and SGs in the base case.

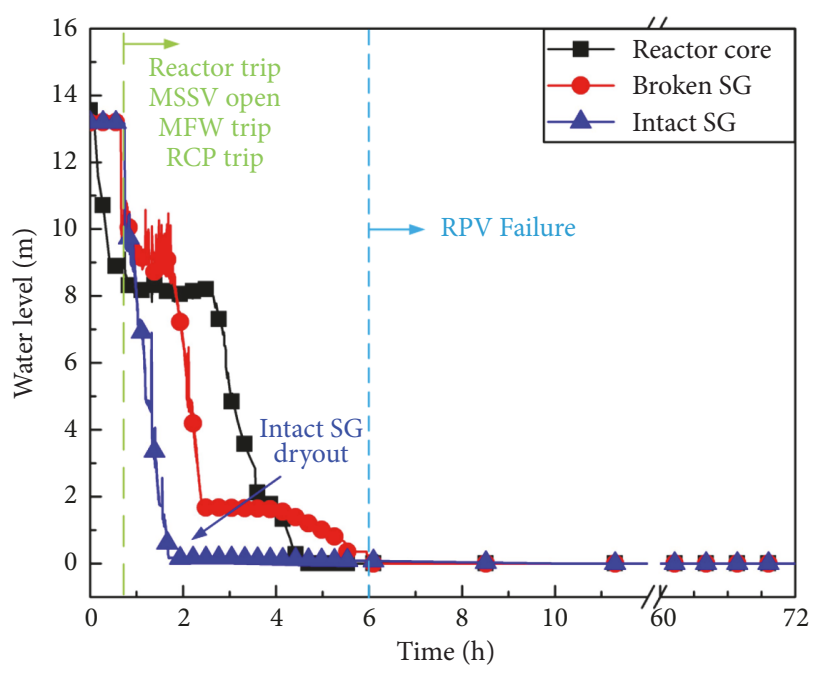

FIgURE 7: The water level of the RCS and SGs in the base case.

analysis using RELAP5/MOD3.4 [18]. Following the RPV failure, the reactor core water level decreased down to $0 \mathrm{~m}$.

As mentioned above, the steam of secondary system was released to the environment through MSSV. Figure 8 shows the released steam mass through MSSV in the base case. After MSSV opening due to overpressure of the secondary system, both SGs released steam to the environment. In the intact SG, the most steam was released earlier than in the broken SG. Because the pressure boundary was not broken in the intact SG, the water in the SG was dried out earlier than broken SG. After dryout, increase of the pressure by boiling did not occur anymore. So, the release of the steam was almost stopped at the SG dryout. On the other hand, the steam release through the broken SG continued due to inflow of the primary coolant through ruptured SG tube. The primary system was connected to the broken SG by ruptured SG tube. Thus, the broken SG received sufficient water from primary system until RPV failure. When the RPV 


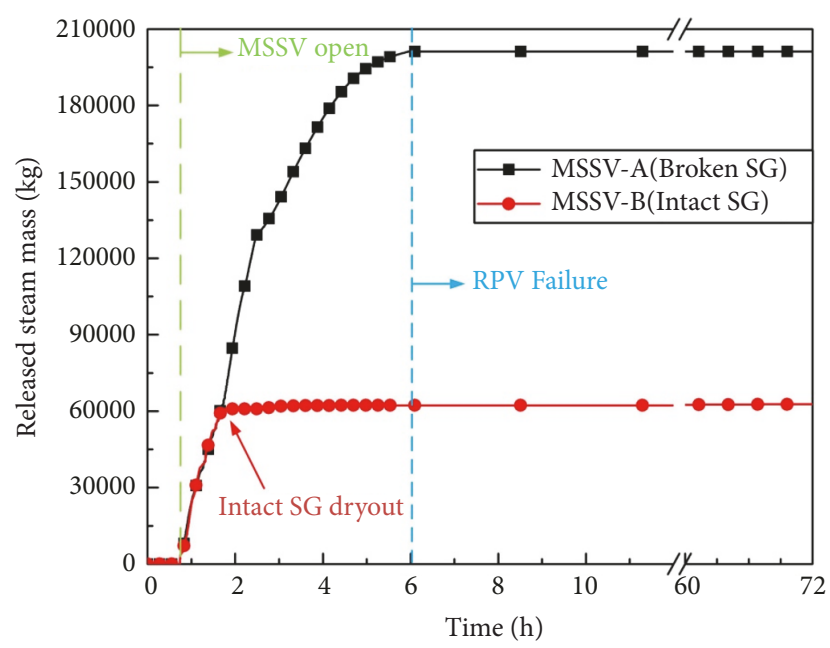

FIGURE 8: Released steam mass through MSSV in the base case.

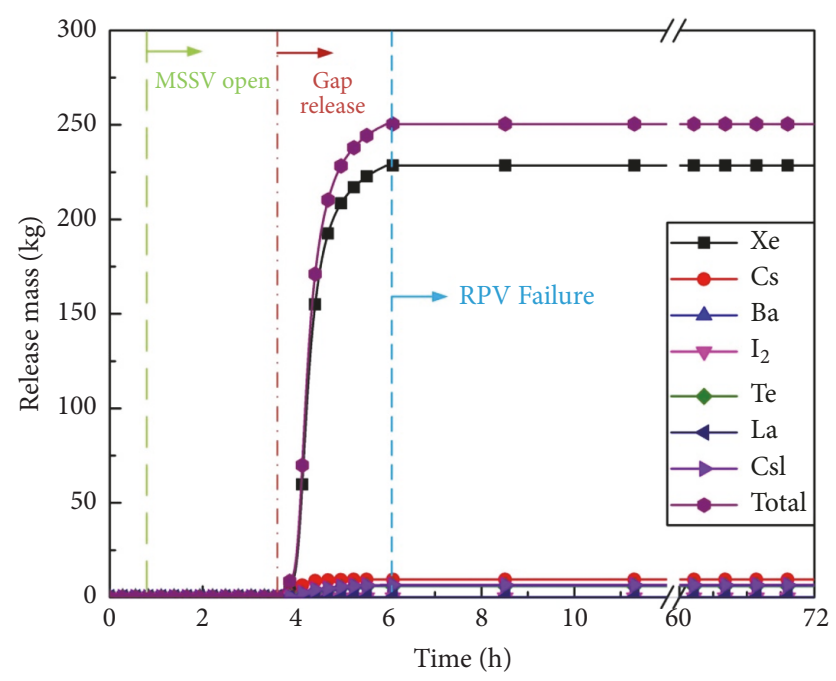

FIGURE 9: The release of mass of radionuclides to the environment in the base case.

failure occurred, a large amount of water and core debris were ejected outside of primary system. Because the pressure was quickly decreased at the time of RPV failure (Figure 6), the steam release through the broken SG was stopped.

In the base case, it was predicted that radionuclides were released to the environment through the MSSV of the broken SG side. The pressure of the secondary system reached the MSSV open pressure at the early stage of accident $(0.74 \mathrm{~h})$, at which the radionuclides were not released to the environment because it existed only in fuel before the gap release. After elapsing gap release time, however, the radionuclides were released to the coolant and transported to the secondary side. So, it was predicted that the radionuclides could be released to the environment after the gap release. But, the release of the radionuclides stopped at the time of RPV failure. It is because the primary and secondary system pressure decreased at the time of RPV failure (Figure 6). So, the MSSV was closed with lower pressure. This is clearly seen in Figure 9, in which the

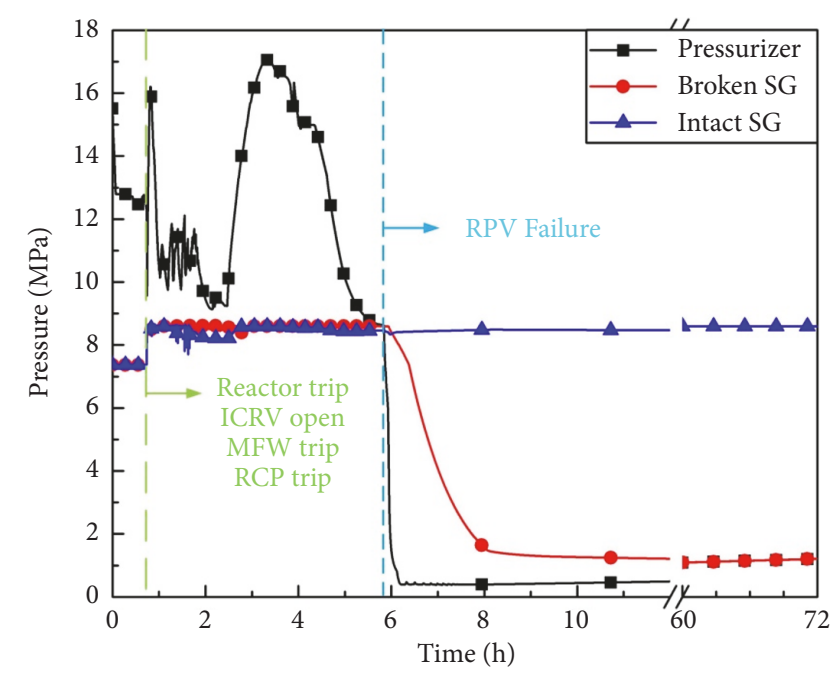

FIGURE 10: Pressure of the RCS and SGs in the ICRV-CNMT case.

release of the radionuclides to the environment stopped after RPV failure.

3.3. ICRV-CNMT Case Simulation. The ICRV-CNMT case is that the steam of the secondary system releases to the upper dome to prevent the release of the radioactive nuclides to environment. The specifications of the ICRV such as flow area are identical to MSSV except exit target. Figure 10 shows the system pressure of the ICRV-CNMT case. Because activation pressure of the ICRV is the same as MSSV, the SG pressure after ICRV opening was kept at 8.6 MPa similar to the base case. Compared to the base case, only exit location of the relief valve is different in the ICRV-CNMT case. Thus, the overall system pressure is similar between the base case and ICRVCNMT case. However, the pressure of the pressurizer and broken SG in the latter period was different between the base and the ICRV-CNMT case. This is because the steam resided in the containment in the ICRV-CNMT case. It caused containment pressure to increase and affected the pressure of the pressurizer and the broken SG after the time of RPV failure.

The ICRV-CNMT case also retains the secondary pressure through the steam release to the outside of the secondary system. However, the steam was released to the inner space of the containment building. Thus, more steam was added to the containment than the base case. The steam mass through the ICRV is shown in Figure 11. The overall amount of the released steam through the ICRV was similar to that through the MSSV in the base case (Figure 8). The total released steam mass out of broken SG and intact SG was $200,715 \mathrm{~kg}$ and $63,140 \mathrm{~kg}$, respectively. It was almost the same with the steam mass of the base case, $201,259 \mathrm{~kg}$ and $62,728 \mathrm{~kg}$ from broken SG and intact SG, respectively. There is no significant difference of the steam mass between MSSV and ICRV because the ICRV was modelled with reference to the MSSV. The MSSV and ICRV were opened by pressure difference between the SG and the environment (MSSV) or containment (ICRV). Unlike the environment, the containment pressure increases because of the released 


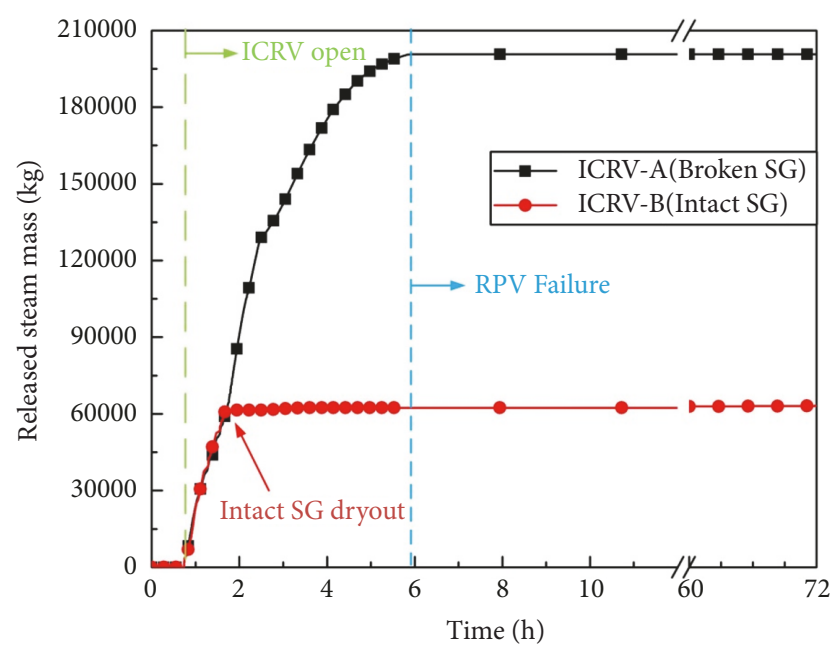

FIGURE 11: Released steam mass through ICRV in the ICRV-CNMT case.

steam from the ICRV. So the released steam mass was only slightly different. Because the intact SG does not have fission product in the SGTR accident, it is no problem that the steam of the intact SG is released to the environment. In this study, however, not only broken SG but also intact SG released steam into the containment for the conservative results. Thus, in the ICRV-CNMT case, total steam of $263,855 \mathrm{~kg}$ was added to the containment compared to the base case.

In the ICRV-CNMT case, the results of the system pressure and released steam mass from SGs were almost the same as the base case. However, the released mass of radionuclides to the environment was different between the base case and the ICRV-CNMT case. In the ICRV-CNMT case, there is no release through the MSSV. Thus, the radionuclides were not released to the environment without containment rupture in the ICRV-CNMT case.

Although the radioactive nuclides were not released to the environment in the ICRV-CNMT case, the steam from the secondary system was released into the containment. It caused an increase of the containment pressure by the released steam. To confirm this effect, the containment pressure was calculated and presented in Figure 12. Figure 12(a) shows the containment pressure in the early stage of the accident until $18 \mathrm{~h}$. When the ICRV opened, the pressure increased because of the released steam of the secondary system. However, the pressure of the base case was not increased because the steam was released to the environment until the time of RPV failure. After RPV failure, a large amount of steam and corium were ejected to the cavity, so containment pressure was peaked. The MSSV and the ICRV did not release the steam anymore. However, the containment pressure increased by boiling off the water in the cavity until cavity experienced a dryout. Although the water was completely evaporated, the pressure increased by the molten corium concrete interaction (MCCI), which, in turn, released a large amount of the gases such as noncondensible gases, carbon monoxide, and hydrogen. In addition, the decay heat of ex-vessel corium increased the containment pressure by the steam expansion in the containment. Finally, the containment pressure was calculated by $0.75 \mathrm{MPa}$ and $1.2 \mathrm{MPa}$ in the base case and the ICRV-CNMT case, respectively, at the $72 \mathrm{~h}$.

3.4. ICRV-RDT Case Simulation. Even if the ICRV-CNMT case did not release the radioactive nuclides to the environment, it caused the containment overpressure. For the effective application of the ICRV, the overpressure needs to be suppressed. Thus, the heat removal of the released steam through the ICRV using the RDT was investigated in this study. The ICRV is connected to the RDT bottom as shown in Figure 5(c). To condense steam in the water, the model in MELCOR was used. MELCOR 2.1 has bubble physics model in the CVH/FL (Control volume hydrodynamics/Flow path) package [19]. It calculates pool scrubbing with RN (Radionuclide) package in MELCOR using SPARC90 model [20]. In this model, condensate steam mass is calculated using the water depth and subcooling of water. Thus, the RDT water volume was changed and simulated in ICRV-RDT cases. Figure 13 shows that the modelling of the RDT differed by water volume.

In the ICRV-RDT cases, the secondary system released steam to the RDT for the heat exchange with the water in the RDT. It was expected that the RDT water condensates the released steam through ICRV and reduces the containment pressure compared to ICRV-CNMT case. However, the containment pressure of the RDT cases was reduced lower than the ICRV-CNMT case as shown in Figure 14. On the contrary, the containment pressure was increased more than the ICRV-CNMT case. In addition, the effects of the RDT water volume were not confirmed in the containment pressure. These results show that the RDT water alone cannot remove the heat of the steam released through the ICRV. The RDT water mass in each case was the evidence of these results.

Figure 15 shows the water mass of RDT in each case. In Figure 15(b), each case of the ICRV-RDT had different water mass of the RDT. Nevertheless, overall tendency is that decreased mass was the same in each case. In the ICRV-RDT$18 \mathrm{~m}^{3}$ case, the water mass rapidly decreased in the early stage unlike the other ICRV-RDT cases. Because the water level of the RDT reached the flow path location, the water spilled over. This phenomenon was not seen in the other ICRV-RDT cases because flow path is far to the surface of water pool.

Compared to the ICRV-CNMT and the base case, the ICRV-RDT case has much transition in the RDT water mass. In Figure 15(a), in the base and the ICRV-CNMT case, the water mass was not changed with time. This is because the steam from the SG was not released into the RDT and so the water mass in the RDT was not changed. On the other hand, the RDT water mass increased slightly after ICRV opened in the ICRV-RDT case by condensation of the steam. Then the RDT water mass decreased rapidly after PSRV opened. At this time, the pressure was reached at the RDT rupture disk break pressure. So the water in the RDT was released to the outside of the RDT. After the time of RPV failure, the release through the PSRV and ICRV was stopped. Thus, the drastic decrease of the RDT water was almost stopped at this time. However, the water of RDT was boiled by the decay heat of the ex-vessel corium and it was accelerated after cavity dryout. 


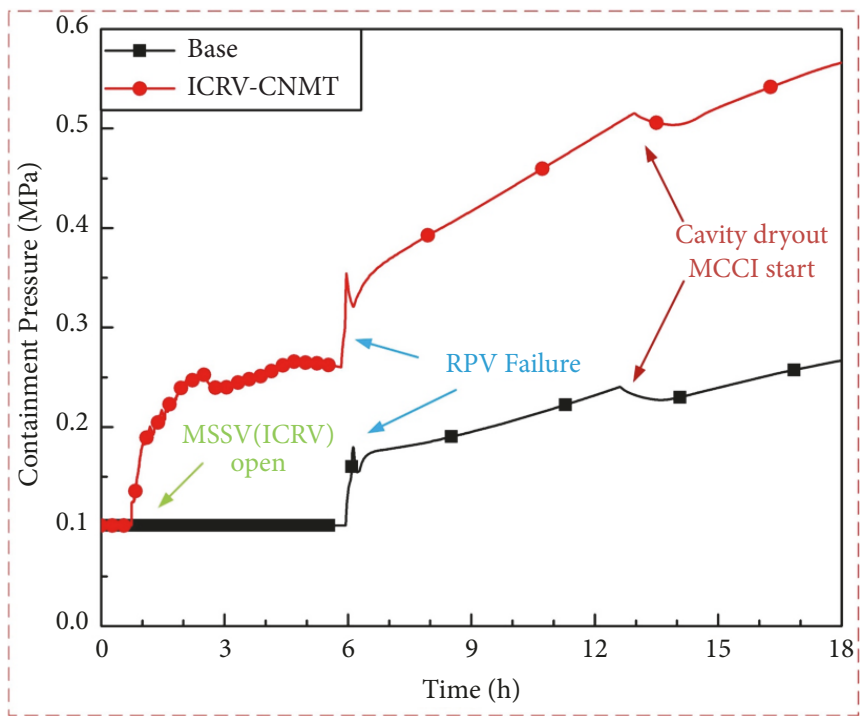

(a)

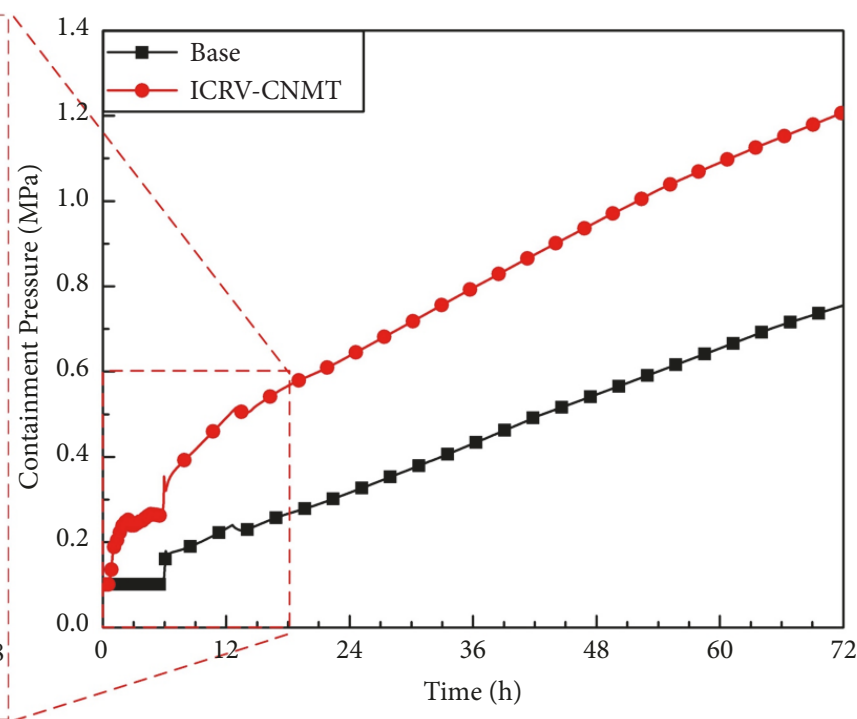

(b)

FIgURE 12: Comparison of containment pressure: (a) first 18 hours; (b) full 72 hours.

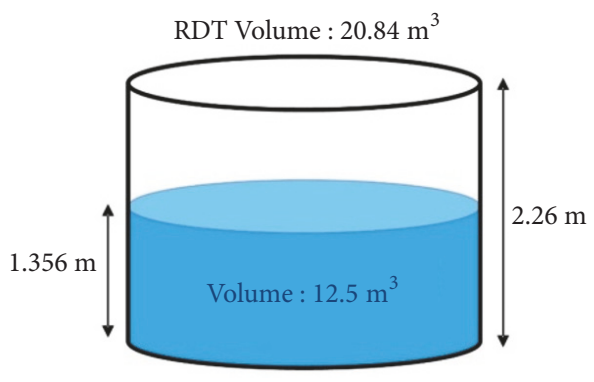

(a)

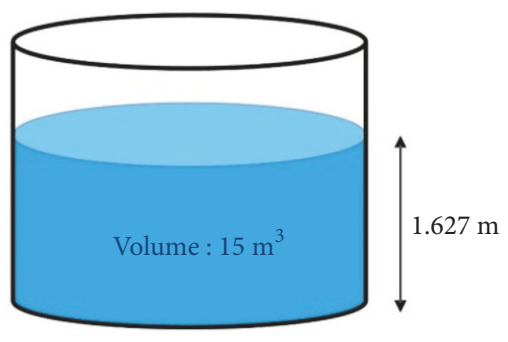

(b)

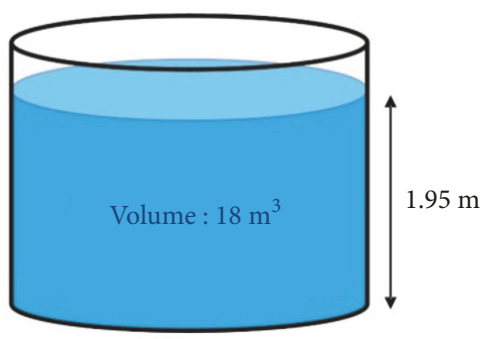

(c)

FIgURE 13: The different water volume in the RDT in each case: (a) $12.5 \mathrm{~m}^{3}$, (b) $15 \mathrm{~m}^{3}$, and (c) $18 \mathrm{~m}^{3}$.

This boiled water of the RDT causes higher pressure in the ICRV-RDT case than the ICRV-CNMT case. Therefore, the depressurization strategy using the RDT is ineffective to the ICRV.

3.5. The Effects of the Cavity Flooding. In the latter period of accident, the overpressure of the containment was caused by two reasons, the heat of the ex-vessel corium and gas generated by MCCI. After the time of RPV failure, the corium was relocated into the cavity which consists of concrete. Then, the massive heat of the corium decomposed the concrete as follows [21, 22].

Dehydration of hydrates $\left(100-850^{\circ} \mathrm{C}\right)$ :

$$
\begin{aligned}
3 \mathrm{CaO} \cdot 2 \mathrm{SiO}_{2} \cdot 3 \mathrm{H}_{2} \mathrm{O} \longrightarrow & 2 \mathrm{CaO} \cdot \mathrm{SiO}_{2}+\mathrm{CaO} \cdot \mathrm{SiO}_{2} \\
& +\mathbf{3 H}_{\mathbf{2}} \mathbf{O}(\mathbf{g})
\end{aligned}
$$

Decomposition of calcium carbonate $\left(600-900^{\circ} \mathrm{C}\right)$ :

$$
\mathrm{CaCO}_{3}+1637 \mathrm{~kJ} / \mathrm{kg} \longrightarrow \mathrm{CaO}+\mathrm{CO}_{2}(\mathrm{~g})
$$

Decomposition of hematite into magnetite $\left(1462^{\circ} \mathrm{C}\right)$ :

$$
6 \mathrm{Fe}_{2} \mathrm{O}_{3}+480 \mathrm{~kJ} / \mathrm{kg} \longrightarrow 4 \mathrm{Fe}_{3} \mathrm{O}_{4}+\mathrm{O}_{2}(\mathrm{~g})
$$

These gases generated by concrete decomposition interact with the corium in the cavity. The reactor core consists of uranium dioxide, zirconium in the cladding, and so on. These materials can react with the steam of high temperature as follows $[23,24]$ :

$$
\begin{aligned}
& \mathrm{Zr}+2 \mathrm{H}_{2} \mathrm{O} \longrightarrow \mathrm{ZrO}_{2}+6.3 \mathrm{MJ} / \mathrm{kg}+\mathbf{2 \mathrm { H } _ { 2 }} \\
& \mathrm{Fe}+\mathrm{H}_{2} \mathrm{O}+3.0 \mathrm{~kJ} / \mathrm{kg} \longrightarrow \mathrm{FeO}+\mathbf{H}_{2} \\
& \mathrm{Si}+2 \mathrm{H}_{2} \mathrm{O} \longrightarrow \mathrm{SiO}_{2}+2 \mathrm{H}_{2}+15 \mathrm{MJ} / \mathrm{kg}+\mathrm{H}_{2} \\
& 2 \mathrm{Cr}+3 \mathrm{CO}_{2} \longrightarrow \mathrm{Cr}_{2} \mathrm{O}_{3}+3 \mathrm{CO}+2.8 \mathrm{MJ} / \mathrm{kg} \\
& \mathrm{Fe}+\mathrm{CO}_{2}+480 \mathrm{~kJ} / \mathrm{kg} \longrightarrow \mathrm{FeO}+\mathrm{CO} \\
& \mathrm{Si}+2 \mathrm{CO}_{2} \longrightarrow \mathrm{SiO}_{2}+2 \mathrm{CO}+14 \mathrm{MJ} / \mathrm{kg}
\end{aligned}
$$

These reactions are oxidation reaction of the metal in the corium. Finally, these MCCI gases caused the containment 


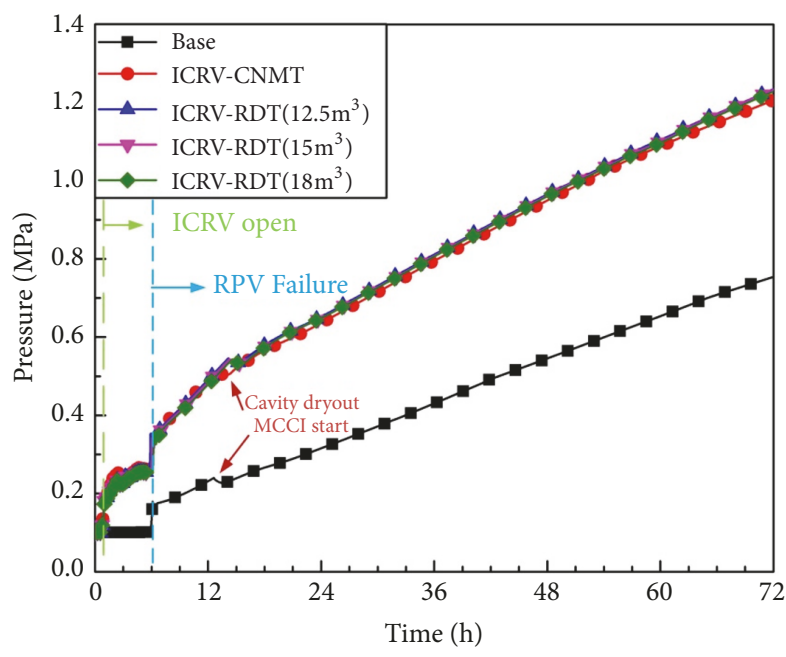

FIGURE 14: Comparison of containment pressure with the base case, the ICRV-CNMT case, and the ICRV-RDT cases.

pressure to be increased. In addition, the decay heat of the ex-vessel corium increases the containment pressure. In this study, the decay heat was calculated by ANS model in the MELCOR [25]. The decay heat of corium expanded the steam in the containment building, and it caused the overpressure of the containment. To diminish these causes of overpressurization, cavity flooding was performed using lowpressure safety injection (LPSI) in this study.

To confirm the effects of cavity flooding, the containment pressure was presented in Figure 16. The cavity flooding was activated from $64,800 \mathrm{~s}$ to $72,300 \mathrm{~s}$ and the water of RWT injected almost 425,000 kg. When the cavity flooding started, the containment pressure decreased by heat removal of the cavity flooding. The pressure was reincreased by the ex-vessel corium. Finally, the containment pressure reached $0.53 \mathrm{MPa}$ and $0.8 \mathrm{MPa}$ in the base-cavity flooding case and the ICRV-CNMT-cavity flooding, respectively. Although it is not low pressure, ultimate containment failure pressure of OPR 1000 with 5\% probability at $95 \%$ confidence level is $1.01 \mathrm{MPa}$ [26]. Therefore, the cavity flooding method is potentially successful as a depressurization strategy because it reduced the containment pressure from $1.2 \mathrm{MPa}$ to $0.8 \mathrm{MPa}$ in the ICRV-CNMT case. Certainly, the depressurization of the cavity flooding was confirmed. However, the effect of depressurization was different with the base case and the ICRV-CNMT case. The pressure was reduced to $0.22 \mathrm{MPa}$ and $0.4 \mathrm{MPa}$ in the base case and the ICRV-CNMT case, respectively, by cavity flooding. It was caused by the difference of the condensate water mass in containment.

Figure 17 shows the steam mass in the containment. In the ICRV-CNMT cases, the steam mass was increased after ICRV open. However, the steam mass in the containment was not the same as released steam mass through ICRV (Figure 11). It is because the released steam was condensed by the structure in containment such as containment wall. After the RPV failure, the steam mass increased by water boiling in the cavity. The steam production rate was steeper in the ICRV cases than the base case because the condensed water before the RPV failure was collected in the cavity in the ICRV cases. These increases were stopped at the cavity dryout, but the MCCI occurred and the steam was generated by concrete decomposition (see (1)). When the cavity flooding occurs, the steam mass in the containment decreased in the cavity flooding cases. In the ICRV-CNMT case, more steam existed in the containment than the base case. Thus, the cavity flooding can interact with more steam, and it caused more reduced steam mass. These differences caused the pressure difference between the base case and the ICRV-CNMT case.

Besides the effect of the decay heat, the MCCI gas affects the containment pressure. Figure 18 shows the total mass of gases generated by MCCI. After RPV failure, little gases were generated by MCCI but the water in the cavity suppressed MCCI until cavity dryout. Then the MCCI occurred and the gases were generated by MCCI. After cavity flooding, the generation of gases was relaxed due to delayed MCCI by heat removal. Although the MCCI gas mass was reduced by the cavity flooding, it cannot explain the difference of the decrement between the base case and the ICRV-CNMT case. Therefore, the pressure difference between the base and ICRV-CNMT cases exists because of the steam in the containment building, not MCCI gas.

After 72 hours of accidents in Figure 18, the mass of MCCI gas reached approximately $60,000 \mathrm{~kg}$ in the base and the ICRV-CNMT cases. In the MELCOR simulation, the MCCI gas consists of $\mathrm{CO}_{2}, \mathrm{CO}, \mathrm{H}_{2} \mathrm{O}$, and $\mathrm{H}_{2}$. It is generated by concrete decomposition reactions ((1) to (3)) or corium oxidation reactions ((2) to (9)). The decay heat of the corium participates in decomposing the concrete, whose example is shown in (3). If the heat transferred to the concrete is totally consumed during chemical reaction of hematite into magnetite $((3))$, the $\mathrm{CO}_{2}$ mass generation rate can be calculated as follows:

$$
\frac{Q-Q_{\text {sen }}}{\Delta H}=\dot{m} \quad\left(Q_{\text {sen }}=m C_{p} \Delta T\right)
$$

$\mathrm{Q}$ is the heat transferred from the corium to the concrete and $\mathrm{Q}_{\text {sen }}$ is the sensible heat of the concrete. $\Delta H$ is the enthalpy of concrete decomposition. $\dot{m}$ is mass generation rate of $\mathrm{CO}_{2}$ gas. $\mathrm{C}_{\mathrm{p}}$ and $\mathrm{m}$ are the specific heat and mass of the concrete, respectively. $\Delta T$ is temperature difference between reaction and initial temperature. The decay heat transferred to the concrete is shown in Figure 19 in the base and ICRVCNMT cases. By using (10), $\mathrm{CO}_{2}$ generation is calculated as $39,000 \mathrm{~kg}$ for 72 hours. However, this approach yields a rough estimate of the MCCI gas. If the other chemical reactions were considered all together, it may reach to $60,000 \mathrm{~kg}$ of the MCCI gas in Figure 18. Similar result could be found in MAAP4 calculation [27].

\section{Conclusions}

The conceptual design of the ICRV was investigated using the MELCOR code in SGTR scenario. The steam of the secondary system was released to the upper dome and the RDT using ICRV. The released mass of the radionuclides was analyzed, and containment pressure was compared in the several explored cases. In addition, the cavity flooding 


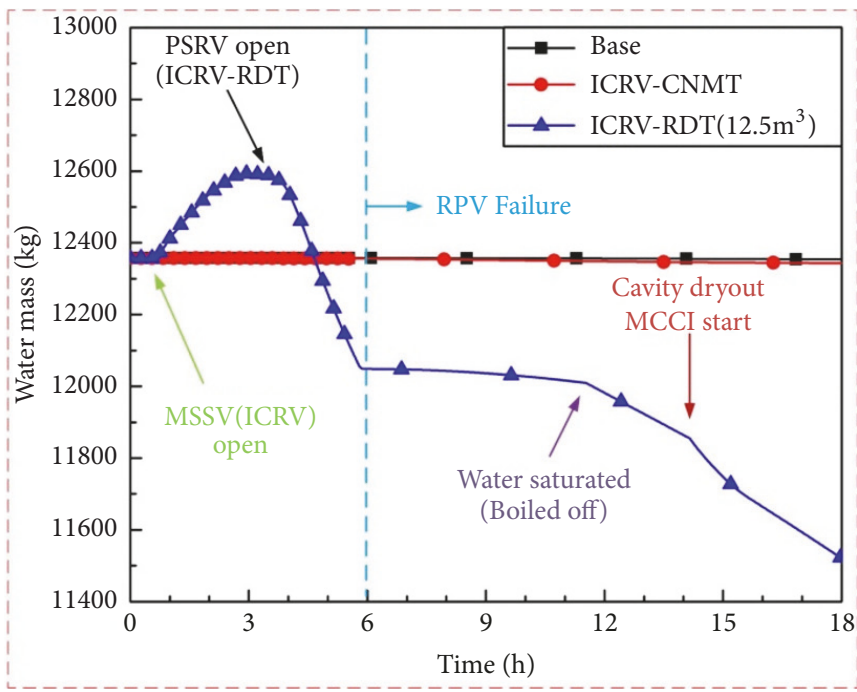

(a)

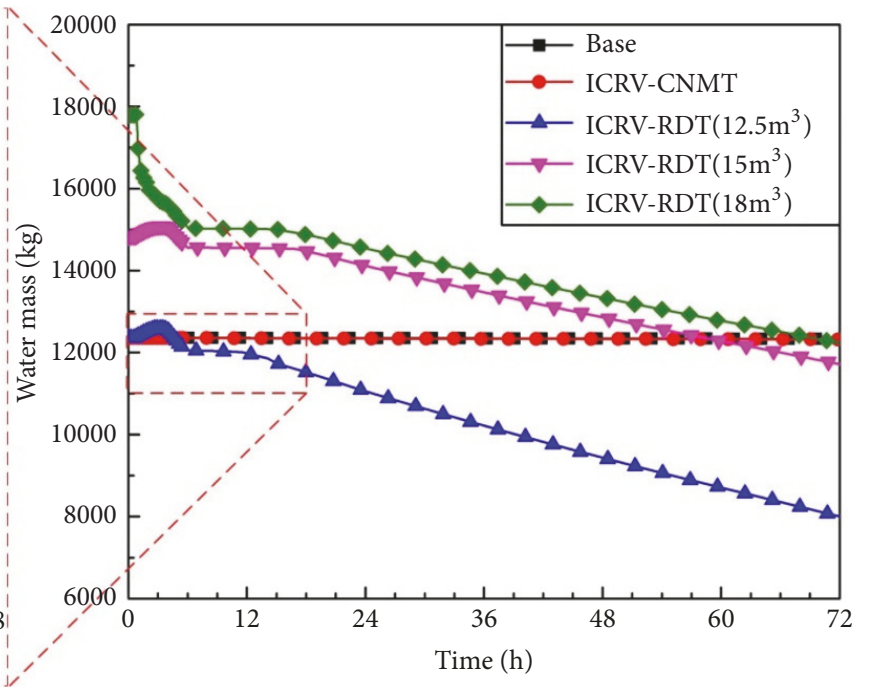

(b)

FIGURE 15: The water mass of the RDT in each case.

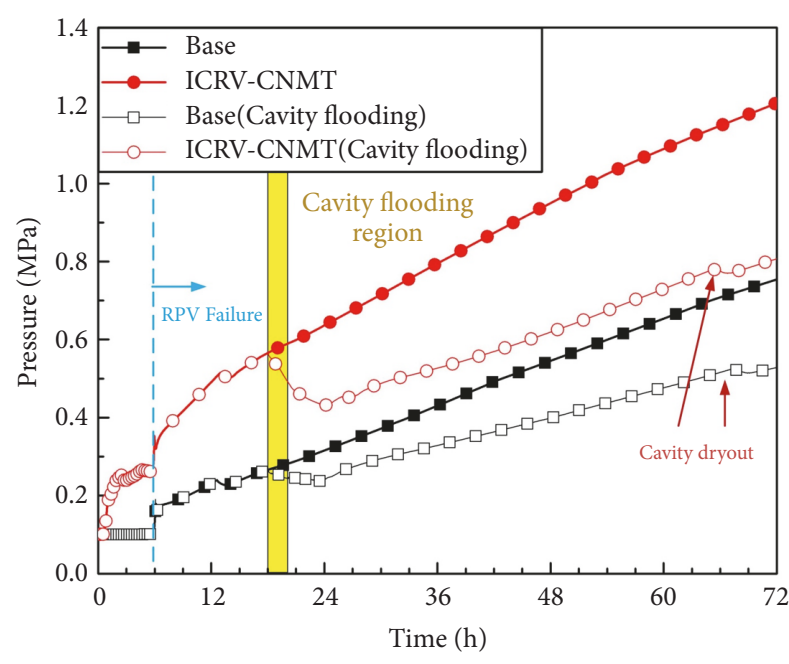

FIGURE 16: The effect of cavity flooding in the containment pressure.

was performed to reduce the adverse effect of ICRV. Major findings in this study and future work can be summarized as follows:

(i) The radionuclides were released to the environment through MSSV in the base case. On the other hand, the incontainment relief valve prevents the release of the radionuclides to the environment.

(ii) As the adverse effect of ICRV, the release steam through ICRV increases pressure in containment building. And it reached 1.2 $\mathrm{MPa}$, which is higher than $0.75 \mathrm{MPa}$ of the base case pressure.

(iii) To reduce the adverse effect of ICRV, depressurization strategy in which the ICRV was connected to RDT was conducted. But it was ineffective because the capacity of the water in the RDT did not satisfy the release steam from steam generator.

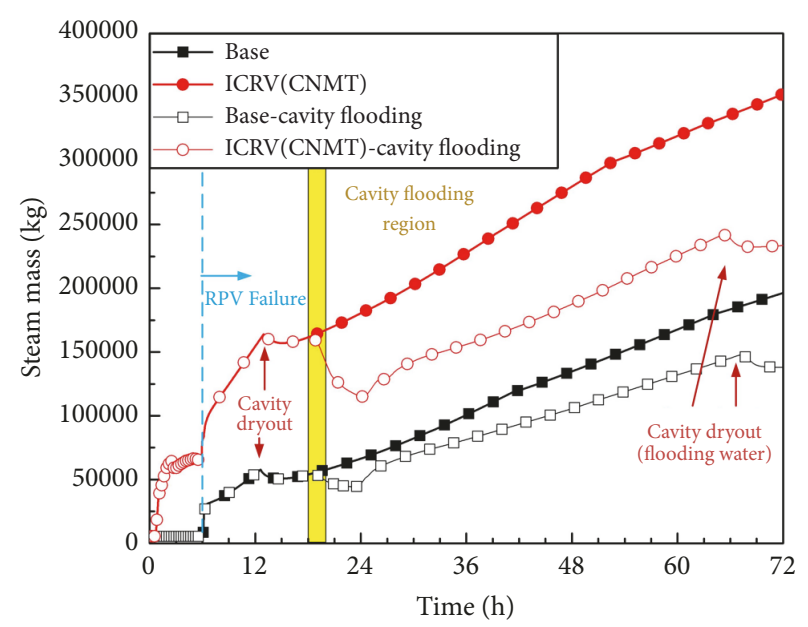

FIGURE 17: The steam mass of cavity flooding in containment.

(iv) The overpressure which is adverse effect of the ICRV can be reduced by cavity flooding. The decay heat removal of the cavity flooding causes the depressurization with the steam condensation. The cavity flooding decreased the containment pressure from 1.2 MPa to $0.8 \mathrm{MPa}$ in the ICRV case.

(v) In the future work, the sensitivity of the specification of ICRV and effects of other safety features should be investigated.

\section{Nomenclature}

ADV: Atmospheric dump valve

AFW: Auxiliary feed water

CET: Core exit temperature

CNMT: Containment

CVH: Control volume hydrodynamics

FL: $\quad$ Flow path 


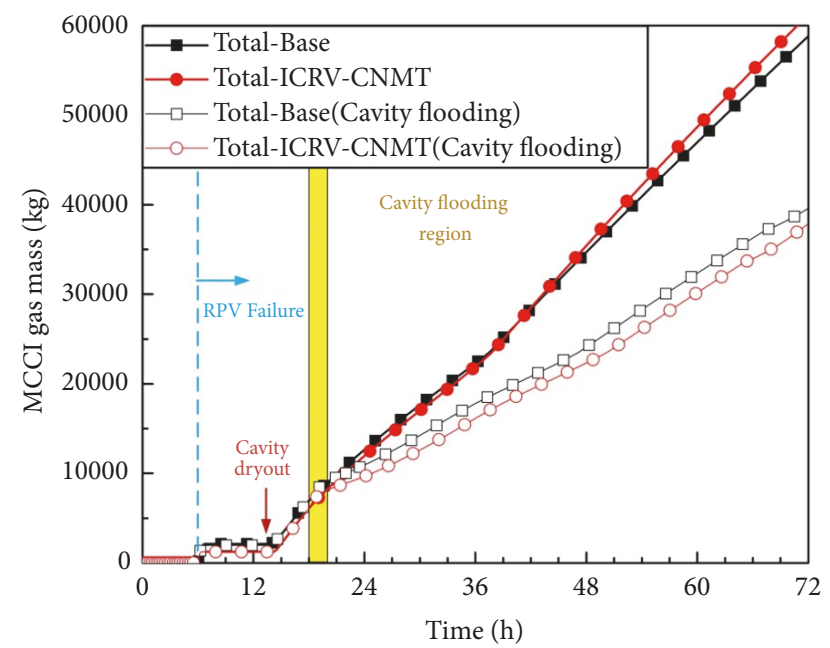

Figure 18: The gases mass generated by MCCI in the cases with/ without cavity flooding.

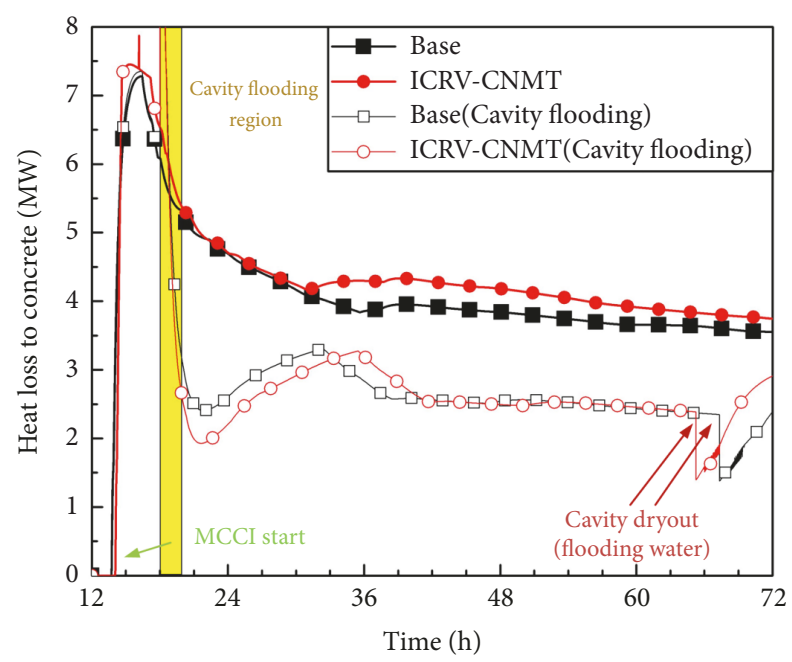

FIgURE 19: The corium heat loss to concrete in the cases with/ without cavity flooding.

FSAR: $\quad$ Final Safety Analysis Report

HPSI: High-pressure safety injection

ICRV: In-containment relief valve

ISLOCA: Interfacing system loss of coolant accident

LPSI: Low-pressure safety injection

LWR: Light water reactor

MCCI: Molten corium concrete interaction

MSSV: $\quad$ Main steam safety valve

NPPs: $\quad$ Nuclear Power Plants

PAR: Passive autocatalytic recombiner

PSRV: $\quad$ Pressurizer safety relief valve

RCS: $\quad$ Reactor coolant system

RDT: Reactor drain tank

RN: $\quad$ Radionuclides

RWT: $\quad$ Refuelling water tank

SBLOCA: Small break loss of coolant accident

SBO: $\quad$ Station blackout
SDS: Safety depressurization system

SG: $\quad$ Steam generator

SGTR: Steam generator tube rupture

SITs: $\quad$ Safety injection tanks

TDAFW: Turbine-driven auxiliary feed water

TLOFW: Total loss of feed water.

\section{Data Availability}

The data used to support the findings of this study are available from the corresponding author upon request.

\section{Conflicts of Interest}

The authors declare that there are no conflicts of interest regarding the publication of this paper.

\section{Acknowledgments}

This work was supported by the National Research Foundation of Korea (NRF) funded by the Ministry of Science \& ICT (MSIT, Korea) [Grants nos. NRF-2017M2A8A4018213 and NRF-2017M2B2A9A02049735].

\section{References}

[1] USNRC, Containment Integrity Research at Sandia National Laboratories: An OverviewNUREG/CR-6906, Sandia National Laboratories, 2006.

[2] J. W. Yang, PWR Dry Containment Issue Characterization NUREG/CR-5567, Brookhaven National Laboratory, 1990.

[3] USNRC, Reactor Safety Study: An Assessment of Accident Risks in U.S. Commercial Nuclear Power PlantsWASH-1400 NUREG75/014, NTIS, 1975.

[4] N. K. Kim, J. Jeon, W. Choi, and S. J. Kim, "Systematic hydrogen risk analysis of OPR1000 containment before RPV failure under station blackout scenario," Annals of Nuclear Energy, vol. 116, pp. 429-438, 2018.

[5] USNRC, Severe Accident Risks: An Assessment for Five U.S. Nuclear Plants, NUREG-1150, NTIS, 1975.

[6] D. Kelly, J. Auflick, and L. Haney, "Assessment of ISLOCA risk-methodology and application to a combustion engineering plant," Tech. Rep. NUREG/CR-5745, 1992.

[7] W. Choi, H.-Y. Kim, R.-J. Park, and S. J. Kim, "Effectiveness and adverse effects of in-vessel retention strategies under a postulated SGTR accident of an OPR1000," Journal of Nuclear Science and Technology, vol. 54, no. 3, pp. 337-347, 2017.

[8] S. Han, T. Kim, and K. Ahn, "An Improvement of Estimation Method of Source Term to the Environment for Interfacing System LOCA for Typical PWR Using MELCOR code," Journal of Radiation Protection and Research, vol. 42, no. 2, pp. 106-113, 2017.

[9] Y. Jin, S.-Y. Park, and Y.-M. Song, "Application of severe accident management guidance in the management of an SGTR accident at the Wolsong plants," Nuclear Engineering and Technology, vol. 41, no. 1, pp. 63-70, 2009.

[10] USNRC, Consequential SGTRAnalysis for Westinghouse and Combustion Engineering Plants with Thermally Treated Alloy 600 and 690 Steam Generator Tubes, NUREG-2195, 2016.

[11] Y. Liao and K. Vierow, "Melcor analysis of steam generator tube creep rupture in station blackout severe accident," Nuclear Technology, vol. 152, no. 3, pp. 302-313, 2005. 
[12] L. L. Humphries, V. G. Figueroa, M. F. Young, D. Louie, and J. T. Reynolds, "MELCOR Computer Code Manuals Volume 1: Primer and Users' Guide.," Tech. Rep. SAND2015-6691R, 2015.

[13] R. O. Gauntt, N. E. Bixler, and K. C. Wagner, "An uncertainty analysis of the hydrogen source term for a station blackout accident in Sequoyah using MELCOR 1.8.5," Tech. Rep. SAND20142210, 2014.

[14] J. Carbajo, "Severe accident source term characteristics for selected Peach Bottom sequences predicted by the MELCOR Code," Tech. Rep. NUREG/CR-5942, 1993.

[15] K.-I. Ahn and S.-Y. Park, "Development of a risk-informed accident diagnosis and prognosis system to support severe accident management," Nuclear Engineering and Design, vol. 239, no. 10, pp. 2119-2133, 2009.

[16] S.-Y. Park and K.-I. Ahn, "SAMEX: A severe accident management support expert," Annals of Nuclear Energy, vol. 37, no. 8, pp. 1067-1075, 2010.

[17] KHNP (Korea Hydro \&amp; Nuclear Power corporation), Shin Kori 1\&2 Final Safety Analysis Report 2008,2008.

[18] M. J. Wang, W. Tian, S. Qiu, G. Su, and Y. Zhang, "An evaluation of designed passive Core Makeup Tank (CMT) for China pressurized reactor (CPR1000)," Annals of Nuclear Energy, vol. 56, pp. 81-86, 2013.

[19] L. L. Humphries, V. G. Figueroa, M. F. Young, D. Louie, and J. T. Reynolds, "MELCOR Computer Code Manuals.," Tech. Rep. SAND2015-6692R, 2015.

[20] P. Owczarski and K. Burk, "SPARC-90: A code for calculating fission product capture in suppression pools," Tech. Rep. NUREG/CR-5765, 1991.

[21] KHNP (Korea Hydro \&amp; Nuclear Power corporation), Probabilistic safety assessment of Wolsung unit 1, 2007.

[22] Z. P. Baznt and M. F. Kaplan, Concrete at high temperatures: Material Properties and Mathematical Models, Essex: Longman Group, 1996.

[23] M. W. Chase, "NIST-JANAF Thermochemical Tables., , Parts I and II, pp," in Journal of Physical and Chemical Reference Data, 4th edition, 1952.

[24] T. Sev and E. Facility, "Molten Core - Concrete Interactions in Nuclear Accidents Theory and Design of an Experimental Facility," VTT, p. 14, 2005.

[25] American Nuclear Society Standards Committee Working Group ANS-5.1, American National Standard for Decay Heat Power in Light Water Reactors, ANSI/ANS-5.1, American Nuclear Society, 1979.

[26] S.-W. Lee, T.-H. Hong, Y.-J. Choi, M.-R. Seo, and H.-T. Kim, "Containment depressurization capabilities of filtered venting system in 1000 MWe PWR with large dry containment," Science and Technology of Nuclear Installations, vol. 2014, Article ID 841895, 10 pages, 2014.

[27] Nan Jiang, Minjun Peng, Wei Wei, and Tenglong Cong, "Strategy Evaluation for Cavity Flooding during an ESBO Initiated Severe Accident," Science and Technology of Nuclear Installations, vol. 2018, Article ID 8680406, 15 pages, 2018. 

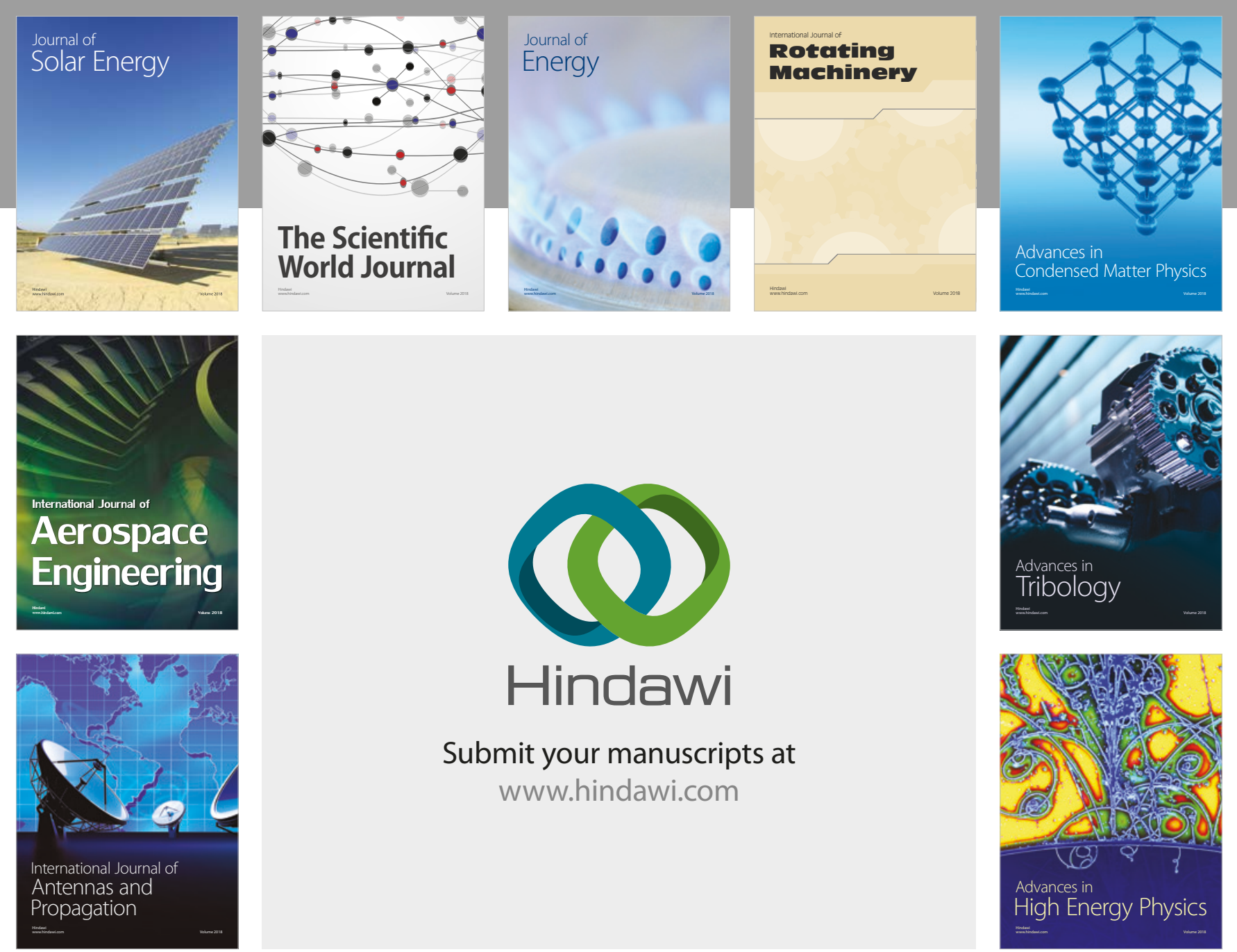

Submit your manuscripts at

www.hindawi.com
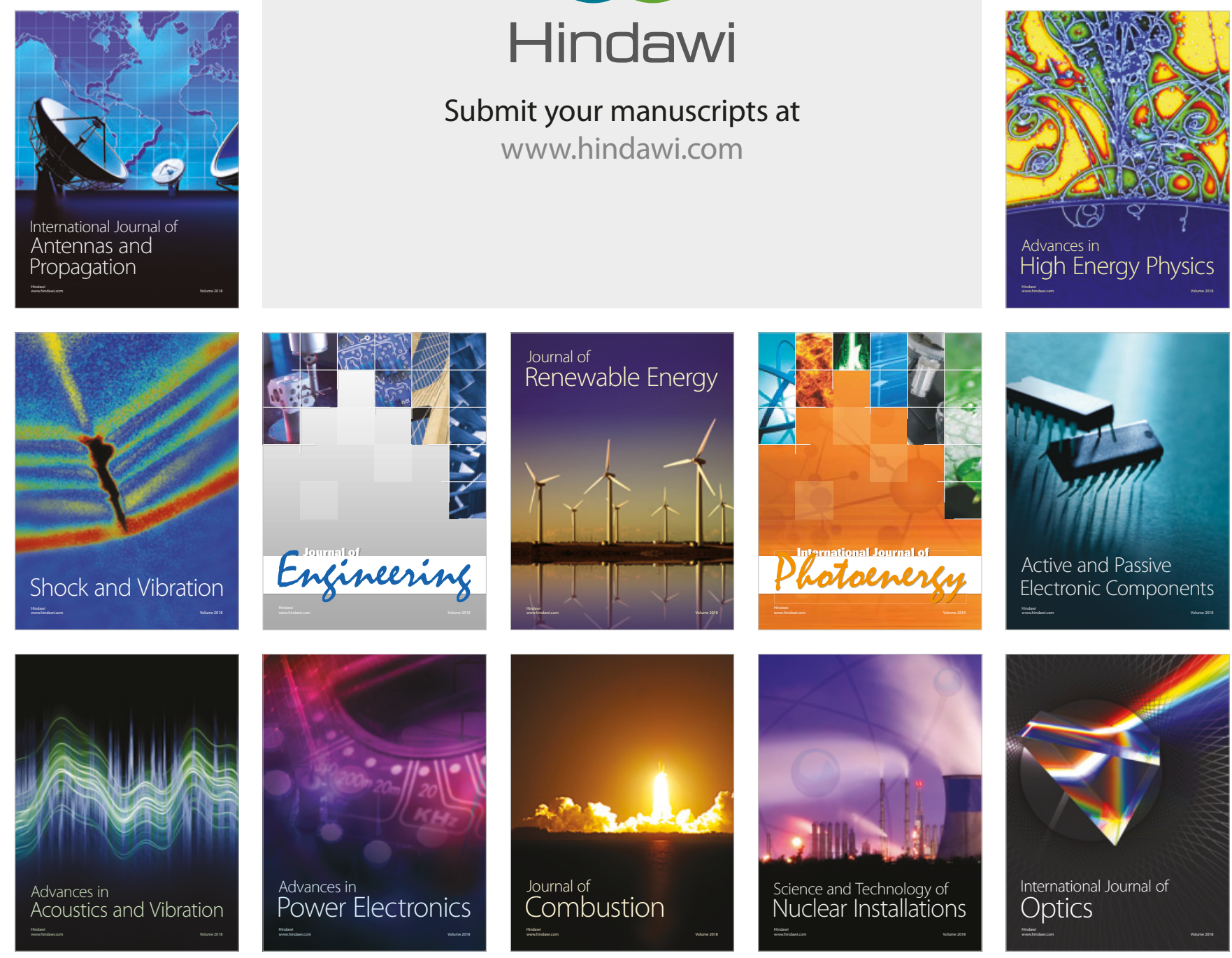